Research Article

\title{
Optimization of Ultrasound-Assisted Extraction of Polyphenol Content from Zea mays Hairs (Waste)
}

\author{
Sarra Aourabi (iD, Mouhcine Sfaira, and Fatima Mahjoubi \\ Laboratory of Engineering, Modeling and Systems Analysis (LIMAS), University of Sidi Mohamed Ben Abdellah (USMBA), \\ Faculty of Sciences, PO Box 1796-30000, Fez-Atlas, Morocco
}

Correspondence should be addressed to Sarra Aourabi; sarra.aourabi1@gmail.com

Received 14 August 2020; Revised 20 November 2020; Accepted 5 December 2020; Published 17 December 2020

Academic Editor: Isabel Del Hierro

Copyright ( $\odot 2020$ Sarra Aourabi et al. This is an open access article distributed under the Creative Commons Attribution License, which permits unrestricted use, distribution, and reproduction in any medium, provided the original work is properly cited.

The aim of this study was to achieve the best extraction efficiency of the hydroethanolic extract of Zea mays hairs. The impacts of ethanol concentration, extraction time, and solvent/material ratio were studied in relation to the performance of Zea mays extracts by ultrasonic extraction at $50 \mathrm{kHz}$ and room temperature. All extracts were quantitatively characterized in terms of polyphenol content. Response surface methodology (RSM) was carried out to optimize the extraction process and increase extraction efficiency. In the experiments, different concentrations of ethanol:water were used. The efficiency of the extraction process was determined from an analysis of variance (ANOVA). The maximum extraction efficiency of the hydroethanolic extraction (31.37\%) and the quantitative value of the polyphenol content (257.87 mg EAG/g extract) were obtained using a treatment time of $40 \mathrm{~min}$, an ethanol:water $(70: 30)$, and a solvent/material ratio $(11 \mathrm{~mL} / \mathrm{g})$. The results obtained indicate that ultrasonic-assisted extraction is an effective method for extracting natural compounds from Zea mays, thus allowing the full use of this abundant and inexpensive industrial waste.

\section{Introduction}

Zea mays hairs (Z. mays, corn silk) are a collection of the stigmas (fine, soft, yellowish threads) from the female flowers of the maize plant contains proteins, vitamins, carbohydrates, $\mathrm{Ca}^{2+}, \mathrm{K}^{+}, \mathrm{Mg}^{2+}$ and $\mathrm{Na}^{+}$salts, volatile oils, and steroids, alkaloids, saponins, tannins, flavonoids, flavones, and flavone glycosides [1,2]. Also, Z.mays hairs, as an essential part of maize, have high pharmaceutical values, for example, it is a urinary emulsifier, which passes stones and gravel from the kidneys and bladder; these hairs work against benign prostatic hyperplasia, cystitis, gout, chronic nephritis, and other similar diseases [3]. In previous studies, a series of phenolic compounds such as rutin, quercetin, epicatechin, vanillic acid, gallic acid, and flavone have been identified and isolated from Z. mays hairs [4-6]. Polyphenols (containing at least two phenolic groups (hydroxybenzenes)) are present in most plant foods and have been considered as "antinutrients" [7, 8]. Pharmacological studies have shown that phenolic compounds have an important function in human health [9], including anticancer actions $[3,10]$ and antioxidant activity [11]. Conventional extraction methods such as maceration, decoction, infusion, reflux, heating, and Soxhlet extraction are used to extract biologically active polyphenols from various plants. However, these conventional extraction methods have generally many disadvantages such as large amount of solvent utilization, long extraction time, and lower extraction yield $[12,13]$. In recent years, new extraction techniques such as ultrasonic assisted extraction (UAE) [14], microwave assisted extraction (MAE) [15], and accelerated solvent extraction (ASE) [16] have been developed to increase the efficiency of the extraction process in terms of time, solvent consumption, and energy consumption [17-20]. Among these methods, the UAE method is advantageous for polyphenol extraction because of the simplicity of the process, low working temperatures $\left(35^{\circ} \mathrm{C}\right.$ to $\left.45^{\circ} \mathrm{C}\right)$, low solvent consumption rate, high recovery of polyphenolic compounds, and low energy 
loss [21]. Polyphenols are highly soluble in various solvents. Methanol and acetone have toxic effects on the human body; in addition, the cost of production is high, so ethanol is still used as an extraction solvent because of its nontoxicity and low-cost availability. The response surface methodology (RSM), especially the Box-Behnken design method, is a modeling tool used to optimize extraction conditions by evaluating multiple parameters and their interaction effects from quantitative data. As a result, RSM can not only statistically optimize complex extraction procedures but also reduce the number of experimental trials [22]. RSM has often been used to optimize the extraction of phenolic compounds from different plant sources [23]. In this work, three factors were used to study the effects of certain parameters on extraction efficiency and the level of polyphenols contained in Z. mays hairs (waste), namely, ethanol concentration, extraction time, and solid/liquid ratio.

\section{Experimental}

2.1. Vegetal Material. Female Z. mays hairs, Poaceae, used for this investigation were collected in September 2018 at the region of Taounate. The botanical identification of the species was carried out in the Laboratory of Biotechnology and Preservation of Natural Resources (BPNR), University Sidi Mohamed Ben Abdellah, Fez, Morocco. The Z. mays hairs were dried at room temperature.

2.2. Method of Extraction. The extracts of the Z. mays hairs were obtained by ultrasounds $(45 \mathrm{~Hz}, 50 \mathrm{~W}, 308 \mathrm{~K})$. The extraction was performed at different ethanol/water percentages, for the amount of material, and for different periods. The extracts were filtered, concentrated under reduced pressure.

\subsection{Effect of Operating Parameters on Extraction Yield.} The fixed extraction conditions are as follows: ultrasonic time $45 \mathrm{~min}$, solvent-to-material ratio $10: 1$, ethanol concentration $70 \%$, ultrasonic temperature $35^{\circ} \mathrm{C}$, and ultrasonic power $50 \mathrm{~W}$. After that, we keep one variable fixed and change the others. The range of variance for each variable is $(35 \mathrm{~min}, 40 \mathrm{~min}, 45 \mathrm{~min}, 50 \mathrm{~min}$, and $55 \mathrm{~min})$ for the extraction time, $(5: 1,10: 1,15: 1,20: 1$, and $25: 1)$ for the liquid material ratio, and $(40,50,60,70$, and $80 \%$ ) for the ethanol concentration. Their impact on the extraction efficiency of the materials was tested separately.

\subsection{Experiment Design for Optimization of Extraction} Method. The RSM is a statistical method that uses quantitative data from an appropriate experimental design to determine the optimal conditions for extraction; first of all, the factors that influence extraction yields and total phenol content were determined and variance ranges of each independent variable were obtained. The results showed that three main factors influence the extraction efficiency, including ethanol concentration $(\%, X 1)$, solvent/material ratio $(\mathrm{mL} / \mathrm{g}, X 2)$, and extraction time $(\mathrm{W}, X 3)$, and these factors were used as independent variables to optimize extraction conditions. We determined the factors and their ranges of variables based on the experiments on the single factors and found that the range of variance for each factor was as follows: ethanol concentration (50\% to $70 \%)$ and solvent/material ratio $(10 \mathrm{~mL} / \mathrm{g}$ to $20 \mathrm{~mL} / \mathrm{g})$. Temperature was not taken into account in this study since the sample was treated at $35^{\circ} \mathrm{C}$ to avoid degradation of heat-sensitive polyphenolic compounds. In this study, the experiments were carried out on the basis of a Box-Behnken design (BBD) plan. The coded values of the experimental factors are indicated in Table 1 . The complete design included 26 combinations, with two repetitions at the center point (Table 2). The data from BBD were analyzed by multiple regressions to fit the following quadratic polynomial model equation:

$$
\mathbf{Y}=\beta_{0}+\sum b_{i} X_{i}+\sum b_{i i} X_{i}^{2}+\sum b_{i j} X_{i} X_{j}
$$

where $\boldsymbol{Y}$ is the predicted response, $\beta_{0}$ is a constant, and $b_{i}, b_{i i}$, and $b_{i j}$ are the linear, quadratic, and interactive coefficients of the model, respectively. Accordingly, $X_{i}$ and $X_{j}$ represent the levels of the independent variables, respectively. The quality of the fitted model was expressed with the coefficient of determination $\left(R^{2}\right)$.

2.5. Determination of the Total Phenolic Content. The total phenols of the $Z$. mays hair extract were estimated using the Folin-Ciocalteu method [24].

2.6. Statistical Analysis. The experimental results of the response surface design were analyzed by Nemrodw. The modeling was started with a quadratic model, including linear, squared, and interaction terms. Significant terms in the model for each response were found by analysis of variance (ANOVA). The experimental data were evaluated with descriptive statistical analyses such as $p$ value. The $p$ values $<0.05$ were considered to be statistically significant. All experiments were conducted in triplicate unless otherwise noted in the text. The purpose of statistical analysis is to determine the different parameters (determination coefficient $R^{2}$ and the effects of the factors) in order to determine the statistical significance of the factors studied.

\section{Results and Discussion}

\subsection{Effect of Single Factor on the Extraction Yield of Z. mays Hairs}

3.1.1. Effect of Extraction Time. The results in Figure 1 indicate that the highest extraction efficiency increases with time and reaches its maximum value at $45 \mathrm{~min}$, but after $45 \mathrm{~min}$, the efficiency decreases. However, when the extraction time is extended, all the cells of the plant will be completely cracked due to cavitation effects, and therefore, 
TABLE 1: Levels of variables for the experimental design.

\begin{tabular}{lccrr}
\hline Independent variable & \multirow{2}{*}{ Symbol } & \multicolumn{2}{c}{ Coded levels } \\
& & -1 & 0 & 1 \\
\hline Ethanol/water $(\%)$ & $\mathrm{X} 1$ & 50 & 60 & 70 \\
Solvent/material ratio $(\mathrm{mL} / \mathrm{g})$ & $\mathrm{X} 2$ & 10 & 15 & 20 \\
Time (min) & $\mathrm{X} 3$ & 40 & 45 & 50 \\
\hline
\end{tabular}

TABle 2: Box-Behnken design (coded) arrangement for extraction of Z. mays hairs.

\begin{tabular}{|c|c|c|c|c|c|c|}
\hline $\mathrm{N}^{\circ} \operatorname{Exp}$ & Rand & Ethanol (mL) & Solvent to material $(\mathrm{mL} / \mathrm{g})$ & Time extraction (min) & Yield (\%) & Polyphenol content (Mg EAG/g extract) \\
\hline 1 & - & 50 & 10 & 45 & 26.35 & 187.24 \\
\hline 2 & - & 50 & 10 & 45 & 26.34 & 187.00 \\
\hline 3 & - & 70 & 10 & 45 & 28.23 & 250.28 \\
\hline 4 & - & 70 & 10 & 45 & 28.19 & 250.25 \\
\hline 5 & - & 50 & 20 & 45 & 16.47 & 126.78 \\
\hline 6 & - & 50 & 20 & 45 & 16.44 & 126.70 \\
\hline 7 & - & 70 & 20 & 45 & 9.32 & 87.45 \\
\hline 8 & - & 70 & 20 & 45 & 9.33 & 87.44 \\
\hline 9 & - & 50 & 15 & 40 & 20.12 & 166.78 \\
\hline 10 & - & 50 & 15 & 40 & 20.11 & 166.77 \\
\hline 11 & - & 70 & 15 & 40 & 12.34 & 151.34 \\
\hline 12 & - & 70 & 15 & 40 & 12.34 & 151.34 \\
\hline 13 & - & 50 & 15 & 50 & 18.83 & 119.54 \\
\hline 14 & - & 50 & 15 & 50 & 18.82 & 119.50 \\
\hline 15 & - & 70 & 15 & 50 & 13.81 & 139.37 \\
\hline 16 & - & 70 & 15 & 50 & 13.81 & 139.33 \\
\hline 17 & - & 60 & 10 & 40 & 24.45 & 240.24 \\
\hline 18 & - & 60 & 10 & 40 & 24.44 & 240.20 \\
\hline 19 & - & 60 & 20 & 40 & 15.24 & 147.52 \\
\hline 20 & - & 60 & 20 & 40 & 15.22 & 147.50 \\
\hline 21 & - & 60 & 10 & 50 & 25.45 & 184.54 \\
\hline 22 & - & 60 & 10 & 50 & 25.44 & 184.52 \\
\hline 23 & - & 60 & 20 & 50 & 11.51 & 119.24 \\
\hline 24 & - & 60 & 20 & 50 & 11.50 & 119.23 \\
\hline 25 & - & 60 & 15 & 45 & 27.34 & 168.87 \\
\hline 26 & - & 60 & 15 & 45 & 27.31 & 168.80 \\
\hline
\end{tabular}

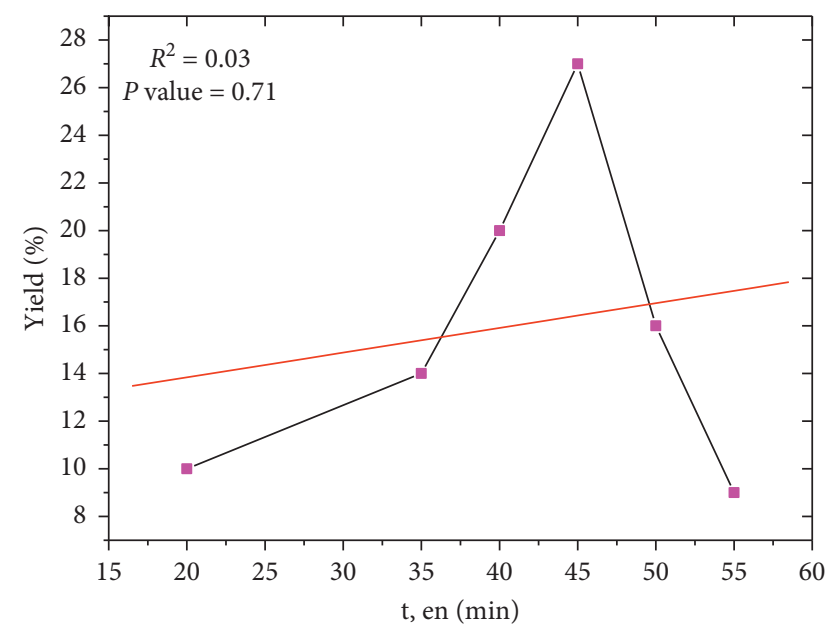

FIgURE 1: Effects of extraction time on yield of extraction.

the extraction yield increases. Therefore, when plant cells decompose, various compounds such as insoluble substances are suspended in the extraction liquid, which reduces the permeability of the solvent [25]. Therefore, polyphenol yield is reduced due to the reabsorption of target components on ruptured tissue particles due to their relatively large specific surface area [26].

3.1.2. Effect of Ethanol Concentration. Water as a nontoxic and inexpensive solvent has widely been used for extraction of active components. It has been observed that sometimes the extraction yield could be improved by adding small percentages of water to the extraction solvent [27]. According to Figure 2, the extraction efficiency of polyphenols has gradually increased to a maximum of $70 \%$. Then, the yield dropped sharply, due to increased volatilization with a high concentration of ethanol.

3.1.3. Effect of Solvent-to-Material Ratio. The maximum polyphenol yield was obtained at a ratio of $15: 1$ between liquid and material (Figure 3). This was consistent with the principle of mass transfer, according to which the driving force during mass transfer was the concentration gradient between solid and liquid, which increases when a higher 


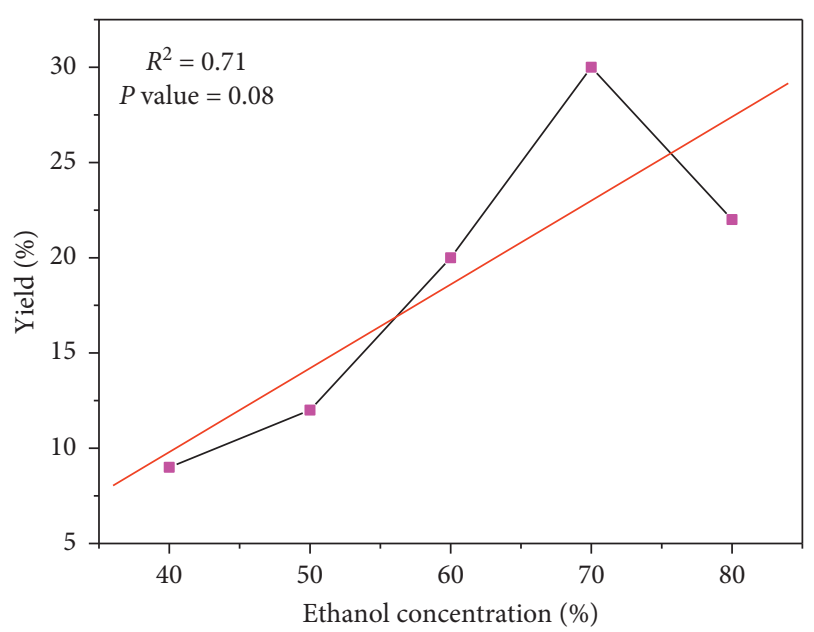

FIGURE 2: Effects of ethanol concentration on yield of extraction.

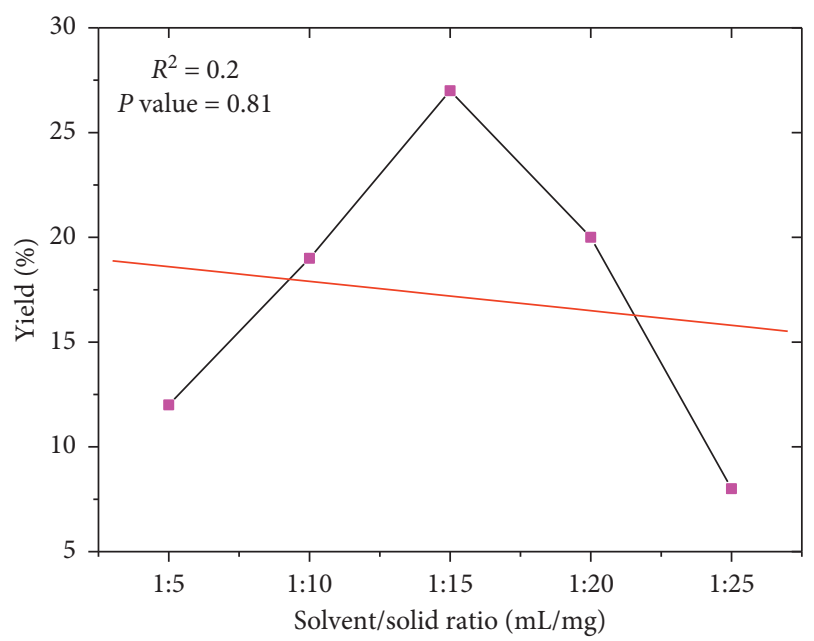

FIGURE 3: Effect of solvent-to-material ratio on yield extraction of extraction.

solvent-to-sample ratio is used [28, 29]. However, an excessive increase in the ratio has also resulted in a decrease in extraction efficiency [30].

\subsection{Statistical Analysis and Model Fitting of Yield Extraction.} The yield of extraction of the experimental design is presented in Table 2. The decoded values of independent variables in the experiment were also presented. Yield extraction of hydroethanolic extract varied from 9.31 to $27.34 \%$ based on different extraction conditions. Multiple regression analysis of variance (ANOVA) was used to check the adequacy and fitness of the developed models. The results of ANOVA are given in Table 3. The results showed that the response of the worth rate $(Y)$ model was highly significant. An item ethanol concentration $(X 1)$, solvent-to-material ratio $(X 2)$, and time of extraction (X3) were significant. The second-order items reached extremely significant level (Table 4 ). The $R^{2}$ and $R_{\text {Adj }}^{2}$ values were 0.977 and 0.964 , respectively. The values are close to 1 which means that the module is validated. The $R_{\text {pred }}^{2}$ which is a measure of how a particular model fits each point in the design, was 0.941, shown strong correlation with actual experimental values.

To calculate the yield of extraction $(Y 1)$ encoded by independent variable ethanol concentration $(X 1)$, solventto-material ratio $(X 2)$, and extraction time $(X 3)$, we used the quadratic multinomial regression equation as follows:

$$
\begin{aligned}
Y 1= & 27.32-2.25 X 1-6.491 X 2-0.318 X 3 \\
& -2.249 X 1 X 2+0.690 X 1 X 3-1.181 X 2 X 3 \\
& -5.062 X 1^{2}-2.179 X 2^{2}-5.990 X 3^{2} .
\end{aligned}
$$

The ANOVA results and regression coefficients are presented in Tables 3 and 4, indicating that the contribution of the quadratic model was significant $(p<0.05)$.

3.3. Statistical Analysis and Model Fitting of Polyphenol Content. The polyphenol content of hydroethanolic extract varied from 87.45 to $266.23 \mathrm{mg}$ EAG/g extract based on different extraction conditions (Table 2). Multiple regression analyses of variance (ANOVA) were used to check the adequacy and fitness of the developed models, and the results of ANOVA are given in Table 5. The results showed that the response of the worth rate $(Y)$ model was highly significant. The $R^{2}$ value was 0.964 (Table 5), indicating that $96.4 \%$ of the total variation in the polyphenols content was attributed to the experimental variables studied, namely, ethanol concentration, extraction time, and solvent-tomaterial ratio. The independent variables, ethanol concentration $(X 1)$, solvent/material ratio $(X 2)$, and extraction time $(X 3)$ are significant $(p<0.05)$. As well as the quadratic variables (X1-1, X2-2, and $X 3-3)$ and interaction variable $(X 1 X 2, X 1 X 3$, and $X 2 X 3)$ are extremely significant $(p<0.05)$ (Table 6).

To calculate the polyphenol content in extract (Y2) encoded by independent variables ethanol concentration $(X 1)$, solvent-to-material ratio $(X 2)$, and time extraction $(X 3)$, we used the quadratic multinomial regression equation as follows:

$$
\begin{aligned}
Y 2= & 168.83+5.53 X 1-49.531 X 2-17.60 X 3 \\
& -29.61 X 1 X 2+8.81 X 1 X 3+6.65 X 2 X 3 \\
& -15.28 X 1^{2}+13.34 X 2^{2}+9.30 .
\end{aligned}
$$

\subsection{Effect of Extraction Parameters on Polyphenol Content.} The response surface and contour plots of the effects of extraction parameters on the polyphenol content are presented in Figures 4 and 5. As shown in Figure 4(a), the efficiency of ethanol concentration on the polyphenol content was evaluated and the results showed that the polyphenol content increased with the increase of ethanol concentration (70\%). It can be concluded that maximum polyphenol content (257.88 mg EAG/g extract) could be achieved when the ethanol concentration and solvent-tomaterial ratio were 68 and $10 \mathrm{~mL} / \mathrm{g}$, respectively, at the fixed extraction time in $40 \mathrm{~min}$. The polyphenol yield increased with an increase of ethanol concentration from $68 \%$ to $70 \%$, 
TABLE 3: Analysis of variance (ANOVA) for the second-order model correlating the content of phenolic compounds with the experimental variables.

\begin{tabular}{|c|c|c|c|c|}
\hline Source & Sum of squares & Degree of freedom & Mean square & $p$ value \\
\hline Regression & 1019.57 & 9 & 113.28 & \multirow{2}{*}{$<0.01^{* *}$} \\
\hline Residual & 24.16 & 16 & 1.51 & \\
\hline Validity & 24.16 & 3 & 8.05 & \multirow{2}{*}{$<0.01^{* * *}$} \\
\hline Pure error & 0.0225 & 13 & 0.00173 & \\
\hline Total & 1043.74 & 25 & - & - \\
\hline
\end{tabular}

$R^{2}=0.977 ; R_{\text {Adj }}^{2}=0.964 ; R_{\text {pred }}^{2}=0.941$.

TABLE 4: Effect estimation, statistical significance, and regression coefficient estimates for phenolic compounds extraction from $Z$. mays hairs.

\begin{tabular}{lccc}
\hline Source & Coefficient & Degree of freedom & $p$ value \\
\hline$b 0$ & 14.186 & - & $<0.01^{* * *}$ \\
$X 1$ & 1.450 & 1 & $<0.01^{* * *}$ \\
$X 2$ & 0.771 & 1 & $0.0451^{* * *}$ \\
$X 3$ & -4.996 & 1 & $<0.01^{* * *}$ \\
$X 1-1$ & 1.178 & 1 & $0.0302^{* * *}$ \\
$X 2-2$ & -0.714 & 1 & $0.207^{* *}$ \\
$X 3-3$ & -0.664 & 1 & $0.271^{* *}$ \\
$X 1-2$ & 0.300 & 1 & $4.36^{*}$ \\
$X 1-3$ & 0.200 & 1 & 12.4 \\
$X 2-3$ & 0.192 & 1 & 13.5 \\
\hline
\end{tabular}

TABLE 5: Analysis of variance (ANOVA) for the second-order model correlating the content of phenolic compounds with the experimental variables.

\begin{tabular}{lccc}
\hline Source & Sum of squares & Degree of freedom & Mean square \\
\hline Regression & 56823.57 & 9 & 6313.73 \\
Residual & 2115.23 & 16 & 132.20 \\
Validity & 2115.53 & 3 & 705.06 \\
Pure error & 0.00378 & 13 & 0.029 \\
Total & 5893.74 & 25 & - \\
\hline
\end{tabular}

$R^{2}=0.964 ; R_{\text {Adj }}^{2}=0.944 ; R_{\text {pred }}^{2}=0.908$.

TABLE 6: Effect estimation, statistical significance, and regression coefficient estimates for phenolic compounds extraction from Z. mays hairs.

\begin{tabular}{lccc}
\hline Nom & Coefficient & Sum of squares & Signif. (\%) \\
\hline$b 0$ & 27.325 & 0.0093026051 & $<0.01^{* * *}$ \\
$b 1$ & -2.257 & 0.0032889676 & $<0.01^{* * *}$ \\
$b 2$ & -6.491 & 0.0032889676 & $<0.01^{* * *}$ \\
$b 3$ & -0.318 & 0.0032889676 & $<0.01^{* * *}$ \\
$b 1-1$ & -5.062 & 0.0061530949 & $<0.01^{* * *}$ \\
$b 2-2$ & -2.179 & 0.0061530949 & $<0.01^{* * *}$ \\
$b 3-3$ & -5.990 & 0.0061530949 & $<0.01^{* * *}$ \\
$b 1-2$ & -2.249 & 0.0046513025 & $<0.01^{* * *}$ \\
$b 1-3$ & 0.690 & 0.0046513025 & $<0.01^{* * *}$ \\
$b 2-3$ & -1.181 & 0.0046513025 & $<0.01^{* * *}$ \\
\hline
\end{tabular}

while decreased when the ethanol concentration was above $70 \%$. Polyphenol yield was largely dependent on the polarity content of solvents and compounds, and a single solvent may not be effective for the extraction of a bioactive compound. Therefore, a combination of ethanol and water was more effective in extracting phenolic compounds than ethanol alone [31]. 70\% of the ethanol showed the highest polyphenol yield, due to lower viscosity and a modification of the plant structure by swelling the matrix, which allowed the solvent to penetrate more completely into the plant material, and these results are in agreement with [32, 33]. Therefore, water acts as a swelling agent for plants, while ethanol would disturb the binding between solutes and plant matrices. Therefore, the mixture of water and ethanol showed the best performance for the extraction of phenolic compounds among all the extracts used; these results are in 


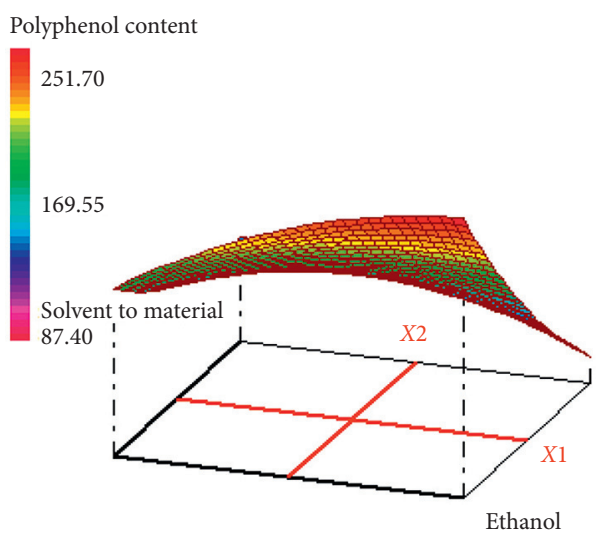

(a)
Polyphenol content

258.70

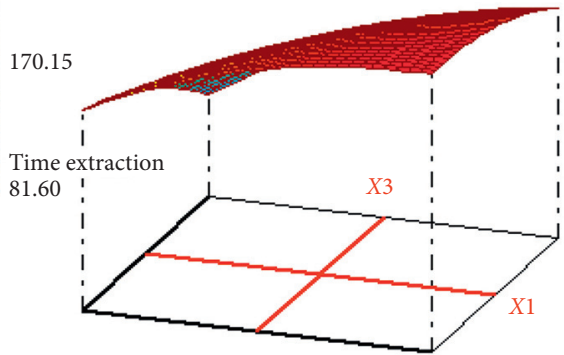

Ethanol

(b)

Polyphenol content

258.50



(c)

FIGURE 4: Response surface for the effect of independent variables on polyphenol content in hydroethanolic extract. (a) Response surface graph showing interaction between solvent-to-material ratio (X2) and ethanol concentration (X1); (b) response surface graph showing interaction between extraction time $(X 3)$ and solvent-to-material ratio (X2); (c) response surface graph showing interaction between extraction time $(X 3)$ and ethanol concentration $(X 1)$.



(a)

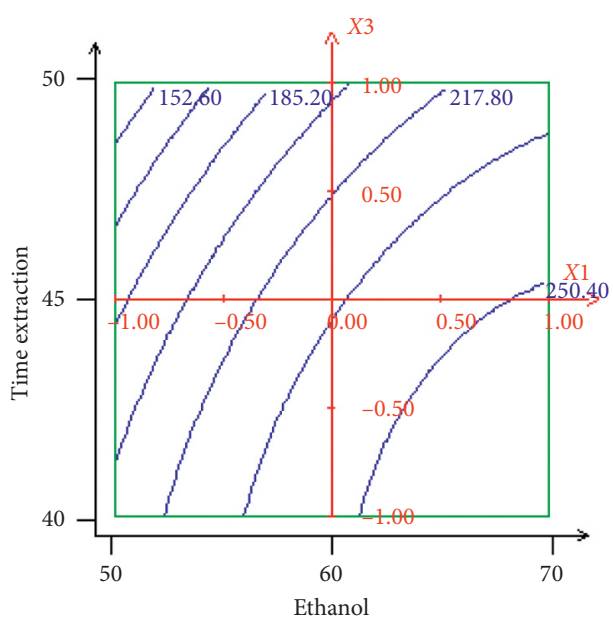

(b)

Figure 5: Continued. 




(c)

FIGURE 5: Contour plots for the effect of independent variables on polyphenol content in hydroethanolic extract. (a) Contour plot graph showing interaction between solvent-to-material ratio $(X 2)$ and ethanol concentration $(X 1)$; (b) contour plot graph showing interaction extraction time $(X 3)$ and solvent-to-material ratio (X2); (c) contour plot graph showing interaction between extraction time (X3) and ethanol concentration $(X 1)$.

agreement with [34]. As for the effect of solvent-to-material ratio of the polyphenols yield, the yield increased with increasing the solvent-to-material ratio from 10 to $15 \mathrm{~mL} / \mathrm{g}$ and decreased after $15 \mathrm{~mL} / \mathrm{g}$. The interaction effect of extraction time and ethanol concentration on the polyphenols content is presented in Figure 4(b). It was found that maximum polyphenol content is achieved when the ethanol concentration was $70 \%$ and the extraction time was $50 \mathrm{~min}$ fixed solvent-to-material ratio at $10 \mathrm{~mL} / \mathrm{g}$. The interaction effect of extraction time and solvent-to-material ratio of the polyphenol content, at a fixed ethanol concentration of $70 \%$, is also presented in Figure 4(c). It was found that maximum polyphenol content is achieved when the extraction time was $41 \mathrm{~min}$ and the solvent-to-material ratio was $10 \mathrm{~mL} / \mathrm{g}$. It is concluded that the ethanol concentration, the solvent-tomaterial ratio and extraction time have a significant interaction effect.

\subsection{Effect of Extraction Parameters on Yield Extraction.} In Figures 6(a) and 7(a), when the 3D response surface plot and the contour plot were developed for the extraction yield of hydroethanolic extract, with varying extraction time and ethanol concentration at fixed solvent-to-material $15 \mathrm{~mL} / \mathrm{g}$. At a definite ethanol concentration, the yield of extraction decreased slightly with the increase of ethanol concentration and extraction time. The highest extraction yield occurred in ethanol concentration of $57 \%$ and extraction time of $45 \mathrm{~min}$ [35]. In Figures 6(b) and 7(b), when the 3-D response surface plot and the contour plot were developed for the recovery of hydroethanolic extract with varying ethanol concentration and solvent-to-material ratio at fixed extraction time at $45 \mathrm{~min}$, it can be seen that maximum recovery in yield of extraction can be achieved when ethanol concentration and solvent-to-material ratio were $59 \%$ and $15 \mathrm{~mL} / \mathrm{g}$, respectively. Figures 6(c) and 7(c) show the effect of the solvent-tomaterial ratio and extraction time on the extraction yield of hydroethanolic extract at a fixed ethanol concentration of $60 \%$. The yield of hydroethanolic extract was decreasing evidently as the increasing of solvent-to-material ratio and nearly reached a peak at the highest extraction time tested. It can be seen that maximum recovery of hydroethanolic extract can be achieved when plant material-to-solvent ratio and extraction time were around $10 \mathrm{~mL} / \mathrm{g}$ and $47 \mathrm{~min}$.

3.6. Verification of Predictive Models. Applying the methodology of RSM, the optimum level of various parameters was obtained and it indicated that extraction time $40 \mathrm{~min}$, ethanol concentration of $70 \%$, and solvent-to-material ratio of $11 \mathrm{~mL} / \mathrm{g}$ give a maximum of polyphenols content of $257.86 \mathrm{mg} / \mathrm{g}$ and yield extraction $31.37 \%$. These optimal conditions could be considered as optimum as well as feasible conditions. To compare the predicted result with the practical value, the rechecking experiment was performed using some extraction condition. The value obtained from real experiments, demonstrated the validity of the RSM model, since there were no significant $(p>0.05)$ differences (Table 7 ). The strong correlation between the real and the predicted results confirmed that the response model was adequate to reflect the expected extraction conditions. 


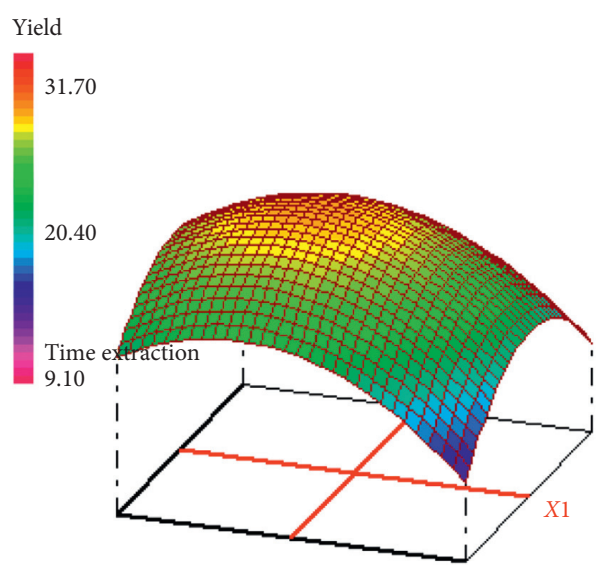

Ethanol

(a)

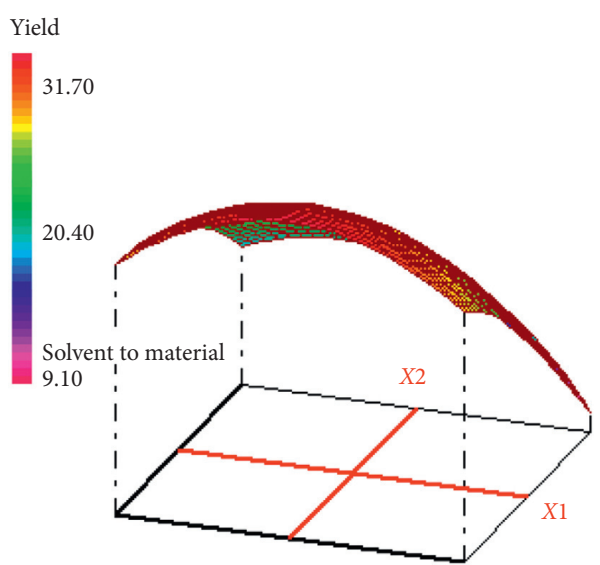

Ethanol

(b)

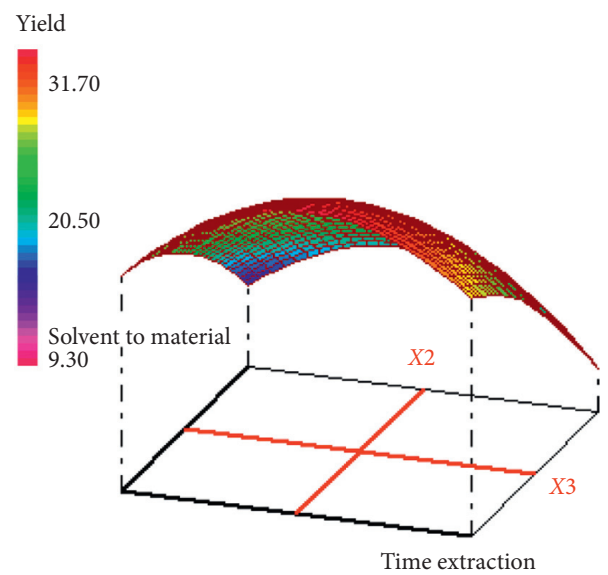

(c)

FIGURE 6: Response surface for the effect of independent variables on extraction yield. (a) Response surface graph showing interaction between extraction time $(X 3)$ and ethanol concentration $(X 1)$; (b) response surface graph showing interaction between solvent-to-material ratio $(X 2)$ and ethanol concentration $(X 1)$; (c) response surface graph showing interaction between extraction time $(X 3)$ and solvent-tomaterial ratio $(X 2)$.

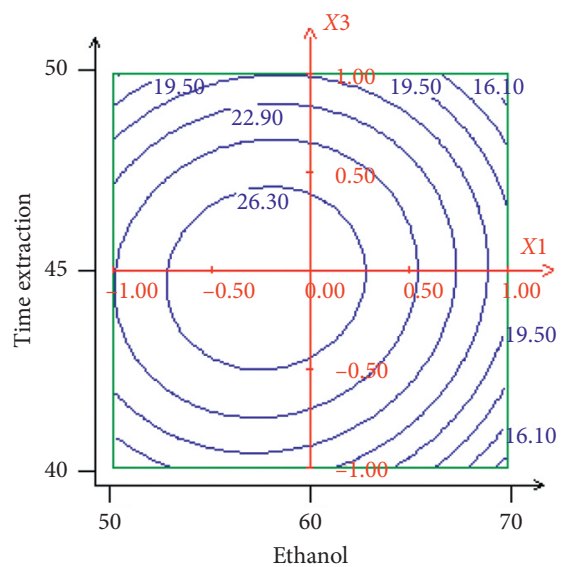

(a)

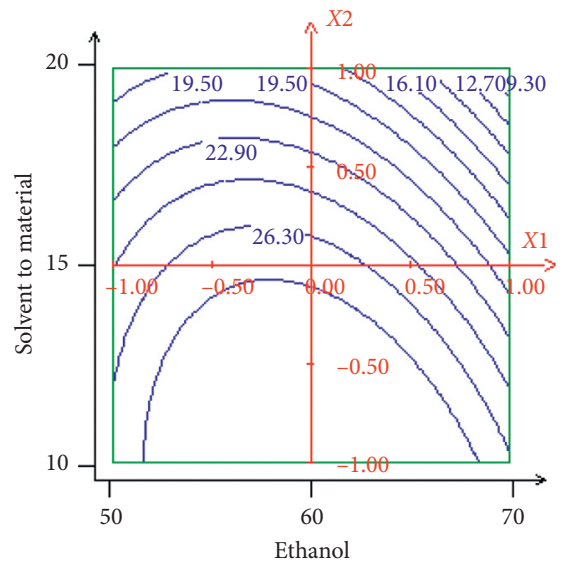

(b)

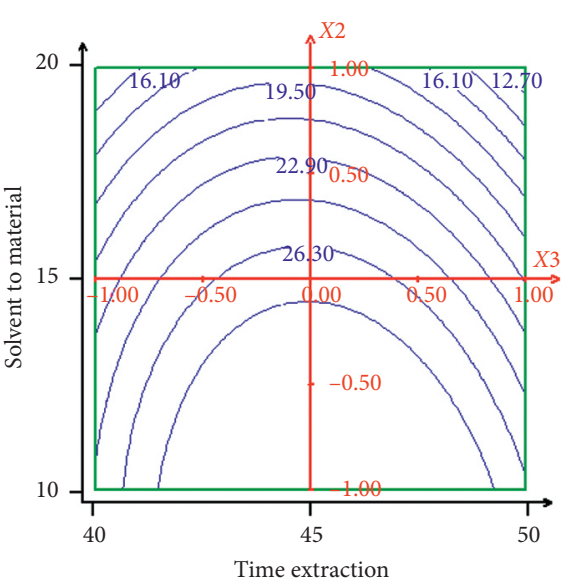

(c)

FIgURE 7: Contour plots for the effect of independent variables on extraction yield. (a) Contour plot graph showing interaction between extraction time $(X 3)$ and ethanol concentration $(X 1)$; (b) contour plot graph showing interaction between solvent-to-material ratio $(X 2)$ and ethanol concentration $(X 1)$; (c) contour plot graph showing interaction between extraction time (X3) and solvent-to-material ratio (X2). 
TABLe 7: Predicted and experimental values of the responses at some extraction conditions.

\begin{tabular}{lccccc}
\hline & Ethanol $X 1(\%)$ & Extraction time $X 3(\mathrm{~min})$ & Solid-liquid ratio X2 & Extraction yield (\%) & TPC (mg EGA/g extract) \\
\hline Optimum conditions & 70 & 40 & 11 & 31.37 & 257.86 \\
Predicted conditions & 70 & 40 & 11 & 30.25 & 255.34 \\
\hline
\end{tabular}

\section{Conclusion}

In this study, the optimization of ultrasound-assisted extraction of hydroethanolic extract of $Z$. mays hairs and calculation of their polyphenols content were conducted. Through response surface methodology (RSM) of yield, the optimal conditions were determined as follows: extraction time $40 \mathrm{~min}$, solid-liquid ratio $11 \mathrm{~mL} / \mathrm{g}$, and ethanol concentration $70 \%$. Under the optimum conditions, the extraction yield of hydroethanolic extract and polyphenol content was $31.37 \%$ and $257.86 \mathrm{mg}$ EAG/g extract, respectively, which allowed higher extraction yields with lower temperature and extraction time when compared with conventional solvent extraction methods. With stable results, this method offered a theoretical basis for industrial and experimental extraction of hydroethanolic extract from Z. mays hairs.

\section{Data Availability}

No data were used to suppor this study.

\section{Conflicts of Interest}

The authors declare that there are no conflicts of interest.

\section{Acknowledgments}

This work was supported by the Laboratory of Engineering, Modeling and Systems Analysis (LIMAS), Faculty of Sciences, University Sidi Mohamed Ben Abdellah (USMBA) Fez.

\section{References}

[1] L. A. Anderson and J. D. Phillipson, Herbal Medicines, A Guide for Healthcare Professionals, Pharmaceutical Press, London, UK, 2nd edition, 2002.

[2] S. Panizza, Plantas que curam: cheiro de mato Local, IBRASA, Soã Paulo, Brazil, 1997.

[3] D. Stagos, G. D. Amoutzias, A. Matakos, A. Spyrou, A. M. Tsatsakis, and D. Kouretas, "Chemoprevention of liver cancer by plant polyphenols," Food and Chemical Toxicology, vol. 50, no. 6, pp. 2155-2170, 2012.

[4] Z. Y. Chen, Y. J. Xu, Y. Yin, X. M. Liu, and X. Q. Li, “Analysis of polyphenol composition of different parts of ear of sweet corn," Food Science, vol. 31, pp. 235-238, 2010.

[5] R. Pedreschi and L. Cisneros-Zevallos, "Phenolic profiles of Andean purple corn (Zea mays L.)," Food Chemistry, vol. 100, no. 3, pp. 956-963, 2007.

[6] L. Jun, W. Cuina, W. Zuozhao, Z. Cheng, L. Shuang, and L. Jingbo, "The antioxidant and free-radical scavenging activities of extract and fractions from corn silk (Zea mays L.) and related flavone glycosides," Food Chemistry, vol. 126, no. 1, pp. 261-269, 2011.
[7] C. Alzueta, J. Treviño, and L. Ortiz, "Effect of tannins from faba beans on protein utilisation in rats," Journal of the Science of Food and Agriculture, vol. 59, no. 4, pp. 551-553, 1992.

[8] M. Longstaff and J. M. McNAB, "The inhibitory effects of hull polysaccharides and tannins of field beans (Vicia faba L.) on the digestion of amino acids, starch and lipid and on digestive enzyme activities in young chicks," British Journal of Nutrition, vol. 65, no. 2, pp. 199-216, 1991.

[9] C. K. R. Vijaya, D. Sreeramulu, and M. Raghunath, "Antioxidant activity of fresh and dry fruits commonly consumed in India," Food Research International, vol. 43, no. 1, pp. 285-288, 2010.

[10] J. Sun, S. Wang, B. Guo, and Y. H. Wei, "Flavonoids of Rhizoma Sparaganii induce S/G2 stage arrest in A549 and MCF-7 cells," Natural Product Research and Development, vol. 23, pp. 224-227, 2011.

[11] X. Wang, Q. Wu, Y. Wu, G. Chen, W. Yue, and Q. Liang, "Response surface optimized ultrasonic-assisted extraction of flavonoids from sparganii rhizoma and evaluation of their in vitro antioxidant activities," Molecules, vol. 17, no. 6, pp. 6769-6783, 2012.

[12] F. Gong, L. Guocheng, P. Chaohai, L. Wenxi, W. Dingyong, and L. Chunxia, "The pharmaceutical society of Japan regular article ultrasound-assisted extraction of pristimerin from celastrusorbiculatus using response surface methodology," Biological and Pharmaceutical Bulletin, vol. 39, pp. 97-103, 2016.

[13] Y. Q. Ma, J. C. Chen, D. H. Liu, and X. Q. Ye, "Effect of ultrasonic treatment on the total phenolic and antioxidant activity of extracts from citrus peel," Journal of Food Science, vol. 73, pp. 115-120, 2008.

[14] J. E. Wong, D. B. P. M. Márquez, G. C. G. Martínez Ávila, C. R. E Belmares, and C. N. Aguilar, "Ultrasound-assisted extraction of polyphenols from native plants in the Mexican desert," Ultrasonics Sonochemistry, vol. 22, pp. 474-481, 2015.

[15] Z. Yang and W. Zhai, "Optimization of microwave-assisted extraction of anthocyanins from purple corn (Zea mays L.) cob and identification with HPLC-MS," Innovative Food Science \& Emerging Technologies, vol. 11, no. 3, pp. 470-476, 2010.

[16] K. S. Woźniak, J. Szypowski, and K. Glowniak, "HPLC analysis of kaempherol and quercetin derivatives isolated by different extraction techniques from plant matrix," Journal of AOAC International, vol. 94, pp. 17-21, 2011.

[17] C. Carrera, M. Palma, A. Ruiz-Rodríguez, and C. G. Barroso, "Ultrasound-assisted extraction of amino acids from grapes," Ultrasonics Sonochemistry, vol. 22, pp. 499-505, 2015.

[18] F. Chemat, Z. Zill-e-Huma, and M. K. Khan, "Applications of ultrasound in food technology: processing, preservation and extraction," Ultrasonics Sonochemistry, vol. 18, no. 4, pp. 813-835, 2011.

[19] Y. Tao and D.-W. Sun, "Enhancement of food processes by ultrasound: a review," Critical Reviews in Food Science and Nutrition, vol. 55, no. 4, pp. 570-594, 2015.

[20] H. Bagherian, F. Z. Ashtiani, F. Fouladitajar, and M. Mohtashamy, "Comparisons between conventional, microwave- and ultrasound-assisted methods for extraction of 
pectin from grapefruit," Chemical Engineering and Processing: Process Intensification, vol. 50, no. 11-12, pp. 1237-1243, 2011.

[21] G. Pan, G. Yu, C. Zhu, and J. Qiao, "Optimization of ultrasound-assisted extraction (UAE) of flavonoids compounds (FC) from hawthorn seed (HS)," Ultrasonics Sonochemistry, vol. 19, no. 3, pp. 486-490, 2012.

[22] A. Brachet, L. Mateus, S. Cherkaoui et al., "Application of central composite designs in the supercritical fluid extraction of tropane alkaloids in plant extracts," Analusis, vol. 27, no. 9, pp. 772-778, 1999.

[23] C. Li, Z. Lu, C. Zhao et al., "Ionic-liquid-based ultrasound/ microwave-assisted extraction of 2,4-dihydroxy-7-methoxy1,4-benzoxazin-3-one and 6-methoxy-benzoxazolin-2-one from maize (Zea mays L.) seedlings," Journal of Separation Science, vol. 38, no. 2, pp. 291-300, 2015.

[24] E. K. Akkol, F. Göger, M. Koşar, and K. H. Başer, "Phenolic composition and biological activities of Salvia halophila and Salvia virgata from Turkey," Food Chemistry, vol. 108, no. 3, pp. 942-949, 2008.

[25] S. Zhao, K. Kwok, and H. Liang, "Investigation on ultrasound assisted extraction of saikosaponins from Radix Bupleuri," Separation and Purification Technology, vol. 55, no. 3, pp. 307-312, 2007.

[26] J. Dong, Y. Liu, Z. Liang, and W. Wang, "Investigation on ultrasound-assisted extraction of salvianolic acid B from Salvia miltiorrhiza root," Ultrasonics Sonochemistry, vol. 17, no. 1, pp. 61-65, 2010.

[27] G. Barbero, A. Liazid, M. Palma, and C. Barroso, "Ultrasoundassisted extraction of capsaicinoids from peppers," Talanta, vol. 75, no. 5, pp. 1332-1337, 2008.

[28] Q.-A. Zhang, Z.-Q. Zhang, and X.-F. Yue, X. H. Fan, T. Li, and S.-F. Chen, "Response surface optimization of ultrasoundassisted oil extraction from autoclaved almond powder," Food Chemistry, vol. 116, no. 2, pp. 513-518, 2009.

[29] S. S. Herodež, M. Hadolin, M. Škerget, and Z. Knez, "Solvent extraction study of antioxidants from Balm (Melissa officinalis L.) leaves," Food Chemistry, vol. 80, pp. 275-282, 2003.

[30] E.-Q. Xia, X.-X. Ai, S.-Y. Zang, T.-T. Guan, X.-R. Xu, and H.-B. Li, "Ultrasound-assisted extraction of phillyrin from Forsythia suspensa," Ultrasonics Sonochemistry, vol. 18, no. 2, pp. 549-552, 2011.

[31] M. Markom, M. Hasan, W. Daud, H. Singh, J. Jahim, and J. M. Jahim, "Extraction of hydrolysable tannins from Phyllanthus niruri Linn.: effects of solvents and extraction methods," Separation and Purification Technology, vol. 52, no. 3, pp. 487-496, 2007.

[32] C. Silva, V. A. S. Garcia, and L. M. S. S. Franciscato, "Ultrasound assisted extraction of bioactive compoundsfrom lichia peels (litchi ChinensisSonn)," Revista Ciências Exatas e Naturai, vol. 18, pp. 81-96, 2016.

[33] P. A. Palsikowski, L. M. Besen, E. J. Klein, C. Silva, and E. A. Silva, "Optimization of ultrasound-assisted extraction of bioactive compounds from B. forficata subsp. Pruinosa," The Canadian Journal of Chemical Engineering, vol. 98, no. 10, pp. 2214-2226, 2020.

[34] S. Aourabi, S. Jennan, M. Sfaira, and F. Mahjoubi, "Optimisation of ultrasound-assisted extraction of phenolic compounds from Ammi visnaga using response surface methodology," International Journal of Pharmaceutical Sciences Review and Research, vol. 10, pp. 2693-2699, 2019.

[35] A. P. Guerra, V. A. d. S. Garcia, and C. D. Silva, "Otimização da extração de compostos fenólicos da casca de manga (tommy atkins) utilizando processo assistido por ultrassom," E-Xacta, vol. 9, no. 1, pp. 103-110, 2016. 